themselves upon us. It certainly is as unscientific and unphilosophical to refuse to locate such points and to test such implications by the development hypothesis as it is, on the other hand, to claim a victory for the sensational interpretation of the hypothesis before all such points of apparent spiritual implication have been resolved. If the former attitude is arrogant, the latter is as certainly presumptuous.

4. In observing young children, a more direct application of the experimental method is possible. " By "experiment" here, I mean both external and internal experiment. In experimenting on adults great difficulties arise through the fact that re-actions are broken at the centre, and closed again by a conscious voluntary act. The subject hears a sound, identifies it, and presses a button. What goes on between the advent of the incoming nerve process and the discharge of the outgoing nerve process? Something, at any rate, which represents a brain process of great complexity. Now, any thing that fixes this sensori-motor connection or simpli. fies the central process, in so far gives greater certainty to the results. For this reason, experiments on reflex re-actions are valuable and decisive where similar experiments on voluntary re-actions are uncertain and of doubtful value. The fact that the child consciousness is relatively simple, and so offers a field for more fruitful experiment, has already been illustrated in what was said above as to the value of suggestion in child-life; it is also seen in the mechanical reactions of an infant to strong stimuli, such as bright colors. ${ }^{2}$ Of course, this is the point where originality may be exercised in the devising and executing of experiments. After the subject is a little better developed, new experimentation will be as difficult here as in the other sciences; but at present the simplest phenomena of child life and activity are open to the investigator.

With this inadequate review of the advantages of infant psychology, it is well also to point out the dangers of the abuse of such a branch of inquiry. Such dangers are real. The very simplicity which seems to characterize the life of the child is often extremely misleading, and misleading because the simplicity in question is not typical but idiosyncratic. Mr. Spencer had a large range of facts in view when he made organic development a progression not only in complexity, but also in definiteness; and the distinction between simplicity which indicates mere absence of complexity and that which indicates definiteness of function as well, applies with force to mental growth. Two nervous re-actions may appear equally simple; but one may be an adaptive reaction, and the other inadaptive. So a state of infant consciousness may seem to involve no complexity or integration, and yet turn out to represent, by reason of its very simplicity and definiteness, a mass of individual or race experience. In other words, children differ most remarkably in the early manifestations of their conscious lives. It is never safe, except under the qualification mentioned below, to say, "This child did, consequently all children must." The most we can usually say in observing single infants is, "This child did, consequently another child may." Yet the uncertainties of the case may be summed up and avoided if certain principles of mental development are kept in view.

1 On the nature and application of experiment in psychology, see my Hz'ldbook of Psychology, Senses and Intellect, 2d ed., pp. 25-31.

2 See t e writer's note in Science, Oct. 31, 1890, p. 247.
(1) In the first place, we can fix no absolute time in the history of the mind at which a certain mental function takes its rise. The observations, now quite extensively recorded, and sometimes quoted as showing that the first year, or the second year, etc., brings such and such development, tend, on the contrary, to show that such divisions do not hold in any strict sense. Like any organic growth, the nervous system may develop faster under more favorable conditions, or more slowly under less favorable; and the growth of mental faculty is largely dependent upon such organic growth. Only in broad outline and by the widest generalization can such epochs be marked off at all.

(2) The possibility of the occurrence of a mental phenomenon must be distinguished from its necessity. The occurrence of a single clearly observed event is decisive only against the theory according to which its occurrence under the given conditions may not occur; that is, the cause of the event is proved not to lie among agencies or conditions which are absent. For example: the very early adaptive movements of the infant in receiving its food cannot be due to volition, but as to what may account for them the case is still open. It is well to emphasize the fact that one case may be decisive in overthrowing a theory, but the conditions are seldom simple enough to make it decisive in establishing a theory.

(3) It follows from the principle of growth itself that the order of development of the mental functions is constant, and normally free from idiosyncrasy: consequently the most fruitful observations of children are those which show that such a function was present before another could be observed. The complexity becomes finally so remarkable that there seems to be no before or after at all in mental things, and, if child processes show stages in which any element is clearly absent, we have at once light upon the law of growth. For example: if a single case is conclusively established of a child's drawing an inference before it begins to use words or significant vocal sounds, the one case is an good as a thousand to show that thought develops to a degree independently of spoken language.

(4) While the most direct results are acquired by systematic experiments with a given point in view, still general observations kept regularly, and carefully recorded, are important for the interpretation a great many such records may ultimately afford. In the multitude of experiences here, as everywhere, there is strength. Such observations should cover every thing about the child, - his movements, cries, impulses, sleep, dreams, personal preferences, muscular efforts, attempts at expression, etc.,- and should be recorded in a regular day-book at the time of occurrence. What is important and what is not, is, of course, something to be learned; and it is extremely desirable that any one contemplating such observations should acquaint himself beforehand with the principles of general psychology and physiology, especially the former.

J. Mark BaLdWIN.

\section{THE INTERMARRIAGE OF THE DEAF, AND THEIR EDUCATION.}

IN his valuable article on the above topic in Science, Nov. 28, Dr. E. M. Gallaudet erroneously states, that, in consid ering the intermarriage of the deaf, the "important fact has been overlooked . . . that with a large proportion of persons 
commonly spoken of as 'deaf-mutes' there is no more likelihood of giving the legacy of deafness to offspring than with perfectly normal people." That fact was pressed in my article to which the doctor alludes, and, as he plainly shows, has been admitted by Dr. Bell. Dr. Bell's classification is doubtless the most philosophic of any yet promulgated, but whether it will be sustained by future investigations remains to be seen. Science is progressive because of the ascertainment of new truths. Its history shows us that the science of to-day may not be accepted as the science of to-morrow. It is too soon to predicate any positive theories upon the statistics as yet collected. The time during which they have been collated is too short, and their accuracy too unreliable (some being merely hypothetical, and many furnished by undiscriminating parties), to warrant deducing positive opinions from them, or the enunciation of any general law based upon them. The investigations of Dr. E. A. Fay, now in prosecution, will no doubt be of greater value than any preceding.

It is scarcely half a score of years since a really intelligent movement in this direction was inaugurated by Dr. Alexander Graham Bell, a philanthropist as well as an eminent scientist and inventor. Statistics relative to the deaf had been taken previously, to some extent, in several institutions, but the inquiries for them had not been general. Statistics, supposed to be reliable at the time of taking them, were by subsequent inquiries, which developed new or additional facts, materially changed; so that former deductions were necessarily reviewed and discarded. One man's lifetime is too short, and his observations too limited, to furnish data upon which to predicate the formulation of a general law. Dr. Bell may have discovered a law governing the offspring of the congenitally deaf persons, or he may have formed an assumption. I think there is as much evidence going to show that an inherent predisposition to deafness exists in some families (using this term in its extended sense), but that it expends its force in a particular line while it remains in others, as there is to show that it perpetuates itself from parent to child. Within my observation there have been more cases of deafness among children only one of whose parents was congenitally deaf than among those both of whose parents were congenitally deaf. I am not certain but that the percentage of the former would also be found less if careful investigation was made. Statistics could be so presented as to show that the intermarriage of the deaf tends to reduce the number of deaf children more effectually than for the congenitally deaf to marry the hearing, or persons whose deafness was acquired after birth, since by the latter means there is more probability of scattering the infirmity than there is in intensifying the predisposition to it by the former. It is undeniable that this predisposition is not obliterated by marriage with one who has it not: hence Dr. Gallaudet's ideal marriage of the congenitally deaf with the hearing, or Dr. Bell's suggestion that they marry the non-congenitally deaf, if there is any truth in the law of heredity, will most tend to increase the number of the deaf; because, where two persons in whom inheres the" probability of laving deaf offspring intermarry, there can result only one family of deaf children, whereas, if they marry hearing or non-congenitally deaf f ersons, two such families may result.

If the congenital deaf-mute must have so much solicitude for his offspring as Dr. Bell and Dr. Gallaudet insist on, shall the hearing person or the non-congenital deaf have none for his? The deaf man or woman has the same right to exercise his judgment in the selection of a partner for life that any other person has. If they desire to compare their family histories with reference to inherent predisposition to deafness, I know of no one who could object, or of no reason why they should not do so, and not as much as that they and all others should consider a phthisical, scrofulous, or cancerous family diathesis. Dr. Gallaudet's argument with reference to the marriage of the deaf with the hearing is good, but is quite as forceful on the other side of the question. Both parties to a marriage have an equal right to forecast the future. No one will deny that a family where one parent is deaf suffers greater disadvantage than one where both parents can hear. Unless there is sincere love between the parties, the hearing person will not enter into such a marriage. A question of this kind is not to be considered from the standpoint of the deaf alone.

After considering Dr. Gallaudet's objection, I still maintain, that, for those deaf persons who improve the opportunities afforded them under the genius of our civilization, deafness may properly be termed only a serious inconvenience. The term "misfortune" is indefinite, and may imply little or much. The loss of an arm is a misfortune, and so is the loss of a finger. I know of no one who says deafness is not a misfortune. My statement to which the doctor objects was to the effect that what was once a calamity (a very strong term) is now only a serious inconvenience. I suppose, as Dr. Gallaudet objects to this, that he uses the term "grave misfortune" in the sense of a calamity. It may or may not be such, according to circumstances. I have known instances in which the visitation of deafness proved to be a stroke of good fortune. I decidedly protest against forever holding up the deaf as victims of a terrible misfortune, and objects of commiseration and charity, after an intelligent public has, at enormous expense, made elaborate, and in some cases palatial, provision for their education, mental, moral, and manual, and while it continues a generous annual outlay for the prosecution of this good and necessary work; and especially do I object to impressing on the deaf themselves, as Dr. Gallaudet's article is calculated to do, that the time is never to come when they shall cease to belong to a special class who are to be looked after by others. I deem it wiser to instill into them the idea that they stand upon the same plane as others, and must provide for themselves as others do; and that, being handicapped with the inconvenience of deafness, they must expect to do a little better than others do in similar walks of life, and thus make themselves desirable to employers. I regard this as one of the important duties of a teacher of the deaf, and of none more emphatically than of one who stands at the head of a college for the deaf, where the choicest spirits and minds culled from a continent are assembled. Surely the public expects this, when the various States and the general government expend more than ten million dollars for buildings and grounds for the accommodation, comfort, and pleasure of the youthful deaf while securing their education, and annually expend a million and a balf dollars for their instruction and maintenance. The traveller in European countries beholds palaces erected by public moneys for kings, princes, and prelates; but it is one of the crowning glories of America that our grand structures are mostly for humanitarian and educational purposes, which enlighten and elevate the common people. Prominent among these are some for the deaf, not to make them a pampered and favored class, but to fit them for an equal chance in life. In many cases this is done to such an extent that they distance their hearing relatives, 
and, from being a dependence, they become the comfort and stay of aged parents and other needy relatives; so that I said I have known some instances where the visitation of deafness was a stroke of good fortune. When I see a lad, solely because of his deafness, taken by kind hands from a home of poverty; transported to an elegant institution where every want is anticipated, both in health and in sickness; for years clothed as comfortably and fed as healthfully as the children of opulence; favored with most skilful instructors and kind care-takers; given books and all school supplies; taught a good mechanical pursuit; graduated with honor; then taken to college, where for a term of years he is given a.course of study as thorough as bearing persons receive and pay for in the best colleges; again graduated with honor; without a day's waiting or search inducted into a lucrative position and an honorable profession; having for these great benefits paid nothing, either himself or his relatives for him (and I consider, that, had he retained his hearing, a life of drudgery would as certainly have been his as it has been of the other members of his family), - I plainly see that deafness to him, though always a serious inconvenience, was a stroke of good fortune.

When I see the deaf daughter of a widow in poverty, after receiving her education, from her earnings purchase a home in which she maintains her mother, lends a helping hand to the other children, and lives for many years in the confidence and regard of refined people, I inquire, though always a serious inconvenience, where is the "grave misfortune" that deafness brought either to this lady or ber friends, especially since older brothers and sisters do not half so much; and it is morally certain that she would not but for the excellent training she received because of her deafness. When a finely educated young man who never heard, tells me, in answer to my inquiry as to how much he laments his deafness, "Not at all," and adds in reply to further inquiries, "Because, so far as I can now see, had I been able to hear, I should have continued to live in the same low plane I was taken from, and in which my brothers, whom I dearly love, still live, but with whom I would not exchange conditions," though a serious inconvenience, I do not see in this visitation of deafness a calamity or even a "grave misfortune." When I see a lady congenitally deaf in her neat, tasty, well-kept, and well-ordered home, with walls decorated with drawings and paintings the work of her own skilful hands, - a happy mother, having on her lap a lovely child, which she is teaching to speak the utterances a-devoted teacher years agone taught her, - and responding to the appeals of a hearing brother for financial aid to support his family, I inwardly ask myself, though always a serious inconvenience, where is the "grave misfortune" in the case of this person, whom I have repeatedly known to express thankfulness for her deafness in the days of her maidenhood?

A mother who had left with me child after child till four of her deaf children were under my care, once unburdened her heart to me, and complained bitterly of the hard Providence that hod inflicted this calamity on her family, but added, "I have one son who hears: he is the apple of my eye and the pride of my life. I shall have great comfort in him." Years passed away. The deaf children completed their education, and were settled in life, when this same mother reminded me of the former conversation, and added, "I wish - had been deaf also: he has made me more trouble than all my deaf children together. If he had been deaf, he would have been under your training, as the others were, and would have been a good man." These are not hypothetical cases, but actual facts, to which there are many others similar. I doubt not all superintendents of institutions for the deaf have seen parallels. It may be urged that these and similar ones are exceptional cases. Grant that they are. All of them at the first were beset with very discouraging prospects. If, in spite of such unfavorable environments, these could rise superior to them, why should the deaf with more favorable conditions be taunted or tortured with the suggestion of grave misfortune? They do not seem so to regard one another. One would suppose that if sympathy for "a brother in distress" would anywhere call forth kindly reception and encouragement, it would be at a college where the subjects of "grave misfortune" are assembled. But to our surprise we find that these frolicsome lads "haze" the new-comers in a sty!e that, while it might not do discredit to a Comanche Indian, certainly does no credit to themselves or their college.

There is a limit to the obligation society owes to its members who start at a disadvantage on the race of life, but just what the limit is has not yet been clearly defined. For the deaf, provision is made for ten years' care, keeping, and in struction by the State governments, and for a college course of from four to six years by the United States Government, to which it is now seriously proposed to add a normal school for the training of teachers. A home for the aged deaf has already been established in one section of the country, which is a most worthy enterprise, and is doing a very humane work. With the school and the college at one end of life, and the home at the other, it would seem that the limit must be nearly attained. But when the normal school is established, it is but a step further to provide an asylum where the intervening years of life may be passed, as is being arranged for the blind. That may be very well for the blind, but I would have no hesitation in denouncing any such project for the deaf as subversive of their best interest and manliness. No one, so far as I know, has seriously proposed such a provision for the deaf (though the inquiry has been made of me as to its practicability), but only a few years ago no one had proposed it for the blind. The tendency seems to be in that direction, and it is about time to call a halt. A "grave misfortune" can be used to plead for a large amount of charity.

Dr. Gallaudet adopts a common fallacy when he states that "all deaf children have the organs of speech." That they have the organ of voice is true, but voice is not speech. The organ of voice is one thing, the organ of hearing is another, but the organ of speech is the union of the two. Speech is the result of the intelligent combined use of the organ of voice and the organ of hearing in a healthy condition. Deaf-mutes have not the important organ of hearing, and, for this cause alone, have not speech. There is no speech of any race, tribe, or clan of men, however barbarous or cultured, that is not based upon hearing; so that we may say the organ of hearing is as essential for speech as the organ of voice. The two are the physical complements of each other in the production of speech. But there is a third element, not physical, necessary for speech; namely, intelligence. This the deaf-mute has perfectly. Nightingales, mocking-birds, and larks have voices that the sweetest and most renowned cantatrices have endeavored to rival in vain. Lions have voices that the basso of the grand opera has never approached. All these and many others of the lower animals have, in addition to voice, the sense of hearing more acute than has ever been known in man; but they have not intelligence sufficient to so use these gifts as to produce 
speech. If it be urged that their vocal organs are not suited to formulate speech, I reply that idiots have perfect human organs of voice and hearing, but have not speech for the same reason that lower animals have not,- the want of in telligence. Not only are the organ of voice and the organ of hearing, with intelligence, necessary for speech, but they must be in a haalthy condition, even to maintain perfect speech after it has been acquired. This is plainly shown by a fact noticed by every observant person, that individuals whose auditory apparatus becomes impaired (though the vocal chords remain in good condition) in middle life, after speech has been fully acquired, and possibly several languages mastered, suffer deterioration of their speech, despite the greatest watchfulness of themselves and their friend. Hearing is a constant monitor, correcting the errors of enunciation, as conscience is, correcting wrong impulses and acts. As surely as searing of the latter results in debasement of the moral life, so surely the failure of the former results in deterioration of speech. If it is difficult for one who once heard perfectly and spoke fluently to retain exactness of utterance with impaired bearing, how much more difficult it must be for one who never enjoyed the advantages of the hearing sense to acquire speech! Yet some do this to a limited degree: but they are marvels of ingenuity and perseverance on the part of their teachers as well as of themselves. It may be safely asserted that no more difficult task can be assigned to mortals than to effect this. To teachers it is a most exhaustive and death-dealing process, when followed up with cases not specially gifted with an unusual aptitude not readily accounted for. Such cases are rare and exceedingly interesting; much more rare than Dr. Gallaudet's admission that "all, or nearly all, deaf children can be taught to speak; but this is precisely as all, or nearly all, normal children can be taught to sing." This is not at all a just comparison, if the doctor means speech intelligible to. general society. Congenitally deaf persons who readily use speech are more nearly analogous in number and production to good poets than to singers. "Poeta nascitur non fit" is a universally accepted adage, whose underlying principle may well be applied to good users of speech who never heard. These statements are made in a spirit of the utmost friendliness to the instruction of such deaf persons in articulation as can acquire it, and are willing to make the necessary effort to that end, and after more than twenty years of earnest labor in this work, in which $I$ have seen more than one faithful teacher give up life as a martyr to it, and after placing a thousand pupils in classes for such instruction, and now having two hundred engaged in it. I have met some very gratifying results, but have experienced mauy disappointments. This was especially true in my first endeavors in articulation work, for I had not then learned that many deaf children who can easily be taught to utter elementary sounds, and associate them with letters, symbols, and diacritical marks, are completely frustrated when they come to use them in combination, and in the intricacies of continuous speech, with punctuation, intonation, and inflection, which give to speech for those who hear its musical quality and pleasurable effect, but of which the congenital deaf-mute has no conception. Speech in a monotone would be very insipid to those who hear, but for the deaf person it has not even a monotone.

Dr. Gallaudet's statements, in his excellent article upon the proper place for the sign-language in the education of the deaf, are so just and true, and the authorities he cites are so reliable and conclusive, as to leave no demand for further arging that point. But in Science of Oct. 17, Mr. B. Engelsman, speaking upon the nature of the sign language, so egregiously blunders in the statement that one is not able to express or receive abstract ideas through the medium of the sign-language, that I am forced to believe, upon the hypothesis that he is a truthful man, that he knows nothing about it, though the temerity of such a procedure, if not admirable, is certainly astounding. It may be safely assumed that two intelligent, well-erucated persons, each having an accurate knowledge of two languages, will, in their daily intercourse with each other, use the one which best suits their purpose and expresses their thought with most precision. I now have in mind two gentlemen, one of whom lost his hearing at six years of age, the other at twelve. Each had $\operatorname{good}$ use of speech before becoming deaf, and bas retained it. Both have received excellent educations, having mastered the literature of several languages, ancient and modern, and also the mathematics and metaphysics of a college course; yet in their daily associaticn, which I bave closely observed for years, they invariab!y use the sign-language, notwithstanding both would be considered good speakers for deaf persons. In answer to my inquiry, one of them says, "I do not use lip-reading or vocal utterance at all when I meet very well educated semi-mutes. I consider such a method a bore." The other of these gentlemen, in reply to the same inquiry, says, in view of his own experience, " Between two deaf persons, sign making, interspersed with finger-spelling, is by far the easiest, readiest, and most satisfactory medium of conversation that man can devise. This mode of conversation is extremely delightful to me. I use in written conversation English, German, and French. By means of signs I can have a discourse addressed to me in philosophy, bistory, literature, seience, theology, or any other topic, and can reproduce it very fully in writing." I know this to be true; for I have repeatedly known him to take notes of my unwritten addresses given in the sign-language, and afterwards furnish them for publication without the omission of a thought, and in better language than I could have expressed it myself, or than was in my mind at the time of delivery. I inquired of a deaf friend whose wife as well as himself has been taught articulation, and is a most acute lip-reader, how much ther use speech and lipreading together. His reply was, "In asking me if I habitually converse with my wife by means of lip-reading, you might as well ask me if we walk down town together on our hands. We do relatively as much lip-reading as that kind of walking." A very intelligent gentleman, living in the city of Chicago, whose wife as well as himself is a semi-mute, one having lost hearing at seven, the other at thirteen, years of age, and both while at the institution having received careful instruction in vocal utterance and lip reading, s: ys, in answer to my inquiry, "Mrs. G. and I never carry on articulation with each other." He goes on to say, "As supplementary information, I may add, that, of the many semi-mutes in the city from the various schools of the country, only three of the whole number are known to use articulation as a sole and constant means of communication with hearing people." A lady congenitally deaf, who is unusually expert in the use of speech, whose husband is a semi-mute and speaks well, replies, "My husband and I use vocal utterance in our daily conversation a great deal, almost half as much as the signlanguage. At meal-time we use our voices in such expressions as 'Please pass the bread,' 'Pass the butter, if you please,' etc., in short sentences; but when we talk at length, we have to use the sign-language, as it is quicker. I have 
always felt so thankful for all you have done in teaching me to talk. It gives us great pleasure to talk to our precious little boy. He understands if I say 'Baby, don't,' when he pulls my hair. He can say 'papa,' is six months old, and weighs twenty pounds." This last is one of those exceptional cases, which we earnestly wish were more numerous among congenital deaf-mutes; that sometimes reward the long patient labor and ingenuity of the teacher. Among hundreds, I have found but few such. It will be noticed that even in this case, where there is both a disposition and an effort to make the most of her acquired speech, signs are necessary to supplement the best she can do with vocal utterance. I have refrained from an expression of opinion on this subject, preferring to give the testimony of persons who are unquestionably competent. The statements quoted were given without the knowledge of the use I should make of them. In view of such testimony, how any honest person can say that the sign-language is incapable of the expression of thought and abstract ideas is incomprehensible. I have never known an individual who endeavored to acquire this language to make such a statement. Even Mr. Engelsman, if he had witnessed at the Convention of American Instructors of the Deaf last summer, as many others did, the translation into the sign-language of the philosophical essay by Mrs. Alice Noyes Smith, simultaneously and concurrently with its reading by its author, would have pronounced it a marvel of exactness, force, and beauty. The sign-language is with that lady vernacular, as she was born and reared with the deaf. Added to this, she has enjoyed the training of her father, Dr. J. L. Noyes, superintendent of the Minnesota Institution for the Deaf, who is, I think, the one most discriminating, critical, and precise master of its language. Mrs. Smith stated that to her this language had all the ease, elegance, and force of spoken language.

In July, 1889, there assembled in the city of Paris, France, a world's congress of the deaf, to consider subjects relating to the welfare of their class, and take such action as might seem to be promotive thereof. This congress was the first of its kind. Its members comprised delegates from France, America, Belgium, England, Ireland, Australia, Sweden, Switzerland, Germany, Poland, and Turkey. They also represented all methods of instructing the deaf, in each of which some of them had received their education. If any company of persons could be expected to speak earnestly and frankly on subjects pertaining to the deaf, it would surely be such a one as this congress. The congress remained in session one week, discussing various questions pertaining to their class. At its conclusion the following preamble and resolutions were unanimously adopted :-

"Whereas the Milan Congress, sitting in solemn conclave, had decided that all deaf-mutes could be taught to speak, and that the pure oral system was superior to all others; whereas, under the influence excited by so august and important a body, changes have been made in some institutions which have a strong bearing on the immediate and future welfare of the deaf; whereas we, though we believe in the utility of the oral system to a certain extent, know that the conclusions arrived at by said congress are arbitrary and unwarranted by experience and facts: resolved, that the system known as the American combined system, which approves of the use of both articulation and signs as the only means by which the greatest number of the deaf can be reached, and the greatest amount of good done, is the best; that we deprecate all such arrangements as aim at the introduction of the oral system in its purest form, and the consequent exclusion of deaf-mute teachers, who have proved themselves fitted for the position; that the above be published to the world as the sentiments of the deaf-mutes gathered from all nations, in the congress held at Paris, July 11-18, 1889."

Such evidence as this is not to be lightly esteemed. It should be duly considered that for the deaf-mute there is no such thing as articulation, though there is articulation by the deaf; for, while he may utter distinct articulate sounds for others to receive, he cannot receive them himself, and is consequently thrown back upon the visible movements of the superficial parts of the organs of voice, which are chiefly the lips. Some mouths are so constructed that many of the movements of the tongue and teeth can also be perceived, but this is by no means frequently the case: hence what is so of ten spoken of as articulation, and is really such to the hearing, is only a lip-sign to the deaf; and there arises the question, which is better, - the small indistinct signs formed by the lips, which represent nothing but sounds, which have no existence for the deaf, or the large, rapid, concise, and ideographic signs made by the hands and arms? Which the preference of the deaf is, need not be asked; for it is universally the fact, and notorious, that deaf-mutes who have been taught by the lip method, and have been shielded from the "contaminating influence of signs"(!) more closely than they have from disease, when opportunity offers, take to signs as naturally as ducklets to the water. They are usually such adepts in the sign-language, that it is obvious to the discriminating observer that they are "old hands at the bellows." It would be as sensible to tell a rustic to blear his eyes on Broadway, or a boy to blear his at the circus, or a belle to wear dark goggles in a millinery-store, as to inhibit the deaf-mute using signs when he meets other deaf-mutes, if he has something to narrate. When fish will not swim in the water, and birds will not fly in the air, we may expect the deaf-mute to disuse signs as a means of interchange of thought. These statements are not made because of objection or opposition to teaching deaf-mutes to articulate or to read lip signs, for to some of them this ability is at times very useful. I have one of the largest companies of deafmutes in the world, receiving such instruction, and I purpose maintaining it in the future as I have done for more than twenty years, during which time $I$ have assigned a thousand of them to teachers for such training. These facts are here set forth that justice may be done the deaf, of whom complaint is often made that they do not do better, by persons who fail to duly appreciate the difficulties they encounter. It should not be a wonder that they do no better, but that they do so well.

Philip G. GILlett.

\section{NOTES AND NEWS.}

Symons's Meteorological Magazine for November contains a climatological table for the British Empire for 1889. The highest temperature in the shade was $109^{\circ}$, at Adelaide, on Jan. 13. For five years Adelaide has recorded the highest temperature in the shade, reaching $112.4^{\circ}$ in 1886 . It had also the highest temperature in the sun, $1 \% 0.7^{\circ}$, and was the driest station during the year, having a mean humidity of 63 per cent. The lowest shade temperature was recorded at Winnipeg, on Feb. $23,-42.6^{\circ}$. Only once does any other station come within twenty degrees of it. It had also the greatest range in the year, the greatest mean daily range $\left(24.5^{\circ}\right)$, the lowest mean temperature, and the least rainfall (14.95 inches). The highest mean temperature was $80.5^{\circ}$, at Bombay; and the greatest rainfall, 73.79 inches, at Trinidad. London was the most cloudy and the dampest station, the mean bumidity being 81 per cent. The brightest station was Malta, which had little more than half the cloud of London. 